\title{
FORMATION OF AUDIOVISUAL COMPETENCE IN TEACHING FOREIGN LANGUAGE TO STUDENTS OF ENGINEERING SPECIALTIES
}

\author{
Olga Efimova, Tatyana Parnikova, Irina Svishcheva, Svetlana Verbitskaya \\ Belgorod State Agricultural University named after V. Gorin, Russia \\ olga.efimova17@yandex.ru,t-parnikova@mail.ru,bsaa-inter2@mail.ru,s_verbitskaya@mail.ru
}

\begin{abstract}
The article reveals the content of the concept of audiovisual competence. To formulate the category of foreign language audiovisual competence in educational activities, it is necessary to take into account the nature of the perception of the language of multimedia. In general, the act of perceiving information and its processing is decomposed into a number of stages, involving the following sequentially proceeding processes: perception correlation with the image stored in memory $>$ recognition $>$ understanding $>$ processing. That is, the influence occurs at the level of consciousness and subconsciousness, rational and emotional. Currently, in accordance with the requirements of existing programs for students of engineering specialties, graduates must not only be proficient in their specialty, but also have good training in a foreign language, that is, possess skills in various types of speech activity - listening, speaking, reading, writing and audiovisualization. As a result of the analysis of interconnections, it seems important to include the following components in the audiovisual competence: information, communication, media-cultural, autopsychological, social interaction and personal development. Thus, within the framework of foreign language intercultural education, audiovisual competence is defined as the ability and willingness to perceive consciously visual cultural information in various media sources, critically interpret and evaluate, use a creative approach in creating cultural images and consciously use them in the practice of intercultural interaction as a mediator of cultures.
\end{abstract}

Keywords: audiovisual competence, engineering education, foreign language, intercultural education.

\section{Introduction}

Currently, in the context of the growing complexity of technical objects and technologies, a large number of new and improvement of existing scientific and technical areas are being developed. All this leads to an increase in intellectual and material costs for applied research and development, and the success of a project is largely determined by the quality of its execution and the qualifications of the performers. The system of agroengineering personnel training and the prestige of the profession in the public mind is becoming one of the important elements of the country's competitiveness in the world economy. Today's agricultural engineer must have a large amount of knowledge, be multidisciplinary, as solving modern multi-agricultural engineering problems requires knowledge in more than one discipline. The training system should develop professional mobility, and this is a transition from one professional position to another, the ability and readiness of a future specialist to adapt to new technological conditions quickly and successfully by mastering new equipment and technologies, constantly replenishing the baggage of knowledge and skills.

Russia actively participates in the engineering world movement. The international economic, cultural and educational space requires a modern agricultural engineer to know a foreign language, which he can use in various activities: obtaining relevant information from foreign language print and electronic sources, participation in international educational programs, participation in conferences and forums dedicated to technical modernization of agriculture, creation of engineering and design, research projects for the development of productive technological processes for enterprises of the agro-industrial complex, interaction with foreign partners in various production processes, work in international teams. The increase in the society's requirements for the level of foreign language proficiency of modern agricultural engineers, while reducing the hours of classroom lessons in a foreign language in nonlinguistic universities, requires changes in the methods of foreign language teaching, the search for forms, means and methods of optimization.

A foreign language, English in particular, is an active subject of the curriculum of the direction of training "Agroengineering", since a modern agricultural engineer needs to navigate the peculiarities of technical English, which is the main language of the scientific environment, including agricultural engineering. The active development of the media is constantly changing the student audience. Not always with an increase in the intellectual level of students. Today's students are generation Z, brought up under the influence of information technology, virtual opportunities. On average, this generation got their first mobile phone at an early school age. They grew up in the world of hyperlinks and spend an 
enormous amount of time on mobile devices. Consequently, their use in the educational process makes it possible to improve the efficiency of material presentation significantly.

A person receives the bulk of information about the world around him through sight and hearing. Audio visualization is a series of interconnected images with or without sound accompaniment and intended for visual and sound perception with the help of appropriate technical devices. The use of audiovisual means in the methodology of foreign language teaching requires constant improvement, the creation of new didactic materials, because their competent use helps increase the effectiveness of learning, and is an effective way to stimulate the educational process [1-4].

Scientists from many countries are engaged in the problem of training engineers, and this is not surprising in the current demand for this specialty. In particular, B. Briede, et al highlighted self-directed learning of university engineering students in context of fourth industrial revolution; S. Nikolaenko, I. Dukulis, et al conducted studies of pedagogical conditions for development of professional selfperfection skills of future agricultural engineers; A. Aboltins, S. Atslega, et al pointed out an opportunity to reduce student dropouts; A. Pastukhov, et al discussed the problem of improving training methods for agricultural engineers [5-7].

\section{Materials and methods}

From the mid-20th century the audiovisual reception of authentic materials begins to dominate the audit, therefore the importance of the development of the skills of audiovisualization increases. In his studies M. Harms (2005) showed that up to $70-80 \%$ of the information a person receives on visual channels and only $13 \%$ on the auditive ones [8]. In most situations, the recipient does not encounter with audition, but with audiovisual reception, since the news on television, and the stories of the interlocutors, the speeches of the actors and lectures are accompanied by a visual series. As noted in his work B. Biechele (1998), with the exception of several cases (conversation on telephone, radio broadcasting, loudspeaker announcements) the auditory perception of speech is also accompanied by visual perception, therefore it seems appropriate to teach students audiovisual reception.

The need to include teaching the skills of audiovisual competence in a foreign language, which stand out along with reading and listening among receptive types of speech activity, was reflected in the document of the Council of Europe "Common European Framework of Reference: Learning, teaching, assessment". Works by N.F. Meshchnova (2004), N. Yu. Kirillina (2006), V.V. Safonova (2010) show that the skills of audiovisualization in a foreign language are necessary for every person who is involved in intercultural communication. For the first time to distinguish visual reception (Seh-Versehen) in a separate type of speech activity was proposed by I. Schwerdtfeger in 1989. B. Bihele proposed the term audiovisual reception (Hör-Seh-Verstehen) to denote the complex process of perceiving information transmitted simultaneously through the visual and auditory channels [9]. In domestic science, along with the term "audiovisual reception" is used "audiovisualization", which was proposed in her work by V. V. Safonova. Following V. V. Safonova, audiovisualization is understood as the process of receptive perception and understanding of audiovisual materials, simultaneously audio information and visual information, as well as those that may contain figurative-schematic and even visual-textual addition [11].

From the point of view of education, the audiovisual competence is the educational result in the form of a combination of knowledge, skills and abilities of auditory and visual perception of foreign language speech, as well as personality traits acquired in the learning process (Fig. 1).

Structure of audiovisual competence

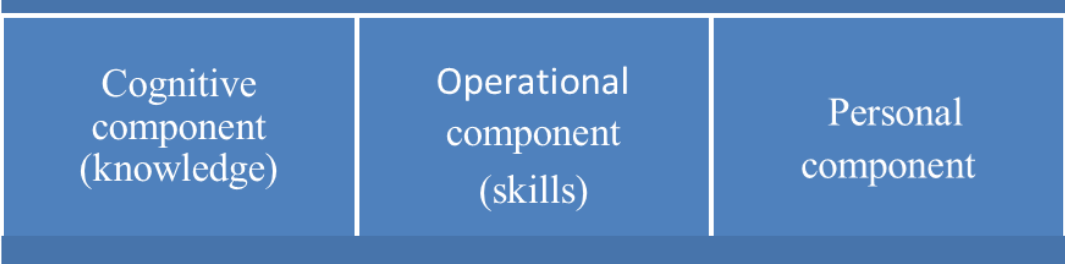

Fig. 1. Structure of audiovisual competence 
Thus, audiovisual competence has all the same components that any competence has: a cognitive component (knowledge), an operational component (skills), and a personality component. The cognitive component (knowledge) assumes the presence of knowledge of oral speech, the main types of oral (monologue and dialogue of various types) statements in the foreign language being studied; sociocultural characteristics of the corresponding sociocultural community; knowledge of the features of the construction of oral statements, depending on their functional and pragmatic type; laws of construction of discourse in the studied foreign language.

The operational component (skills) assumes mastering the skills of oral speech perception in the foreign language being studied; the ability to use strategies and tactics of oral discourse; the ability to perform listening with a global, detailed and selective understanding of foreign language speech, the ability to correlate the viewed video sequence with the text. Skills related to the operational component are divided into auditory and visual perception skills. As for auditory skills, they can be divided into auditory skills at the level of general, complete, detailed and critical understanding, depending on the type of the audio text. The skills of visual perception are divided into the skills of overview audio visualization, the skills of introductory audio visualization, learning audio visualization, critical and information retrieval.

The personal component assumes the readiness and ability for self-development, the transition to self-development and self-assessment, i.e., it is a personal psychological new formation in the aggregate of general cultural, general professional and special competencies, which in unity and interconnection includes, along with cognitive and behavioral aspects, long-term readiness and ability to conduct professional and research activities in a foreign language based on audiovisual content. Long-term readiness includes motivational, emotional-volitional, attitudinal-behavioral and evaluative components, and ability - cognitive and behavioral aspects.

The main characteristics of this structure are its openness, and variability. It can be adjusted depending on the direction of training of future graduates, the emergence of new ways of presenting audiovisual content, the use of elements of virtual and augmented reality in audiovisual works, the development of technical means, etc.

As a result of interviews and questionnaires, three criteria for the formation of audiovisual competence were identified, each manifesting accordingly in terms of indicators.

1. The degree of development of auditive skills and audio visualization abilities is manifested through the following indicators: the ability to systematize existing knowledge, skills, and abilities; understanding the semantic task of perception; adaptation to the conditions of perception; understanding the compositional and semantic structure of statements; expansion of types, genres and functional styles of statements; combination of listening with visualization, etc.

2. Technological readiness presupposes knowledge of methods, techniques and means of forming audiovisual competence, the ability to use this knowledge and methods when organizing work with video.

3. Creative activity in the application of methods, techniques and means aimed at the formation of audiovisual competence is manifested in intellectual and speech activity, the use of intuition, deviation in thinking from traditional and generally accepted schemes, the perception of surrounding reality multiple-valued, and designing elements to new combinations that meet the utility requirements, identifying the missing information, etc.

The generalization of the actual material on the problem under study allowed to describe three levels of formation of the audiovisual competence of students of non-language faculties, depending on the degree of manifestation of criteria and indicators.

The adaptive-reproductive level of formation of audiovisual competence is characterized by an unstable attitude of students to the formation of audiovisual competence when the purposes and objectives of their own activity are defined in general. Students organize communication on a predetermined scheme, algorithm, that is, reproductive. Technological readiness is reproducing, the interpretation of audiovisual competence is absent, or carried out using the algorithm proposed by the teacher.

The interpretive-constructive level of formation of audiovisual competence is characterized by a more sustainable attitude of students to the phenomenon "Audiovisual competence", greater 
purposefulness in organizing the process of forming audiovisual competence, making the need to form audiovisual competence.

A system of knowledge about the methods, devices and means of forming audiovisual competence is formed, students actively use this knowledge, methods and techniques in organizing communication, interpretation of these methods is carried out by students independently with the transition from reproductive forms to search, there are elements of improvisation.

The creative level of formation of audiovisual competence is characterized by a successful creative search, the implementation of the existing experience and creating new combinations on its basis; the ability to see and predict a new problem, quickly move from one category to another, from one solution to another; see analogies; solve the problem originally (adaptation flexibility); give a verbal or visual form the planned shape (audiovisual flexibility).

Criteria and levels of formation of audiovisual competence are in close interaction with functional components and structural elements of the studied phenomenon "audiovisual competence". The set of components and structural elements reveals the specifics of the audiovisual competence of students of non-linguistic faculties. The criteria and levels of formation of the audiovisual competence of students of non-linguistic faculties that we have identified provide a systemic holistic view of the phenomenon under study and serve as a prerequisite for further studying the trends, principles and conditions for the formation of this type of competence.

The basic toolkit of empirical research was the method of questioning, carried out on the basis of the authors' questionnaire, designed to determine the preferences of students in the choice and use of educational content in the educational process. The types of educational content that students use with varying degrees of intensity are highlighted. A rating of the relevance of each type of content has been compiled and the forms of work with it for students are indicated. It is stated that the choice of the type of information resource and its content is determined by the level of development of audiovisual competence among students.

\section{Results and discussion}

In contrast to the students themselves, teachers are inclined to regard the work of students with educational content as reproductive (viewing presentations and video lessons occupy a leading position according to the survey results), from the standpoint of consumers of ready-made information. Despite the fact that participation in creative tasks for the creation of audiovisual content (project, video, presentation) was noted by students in the last place, students rate their activity and productivity of motivation for interacting with educational content higher than their teachers.

The analysis of the methodological reality has shown that in the professional training of agricultural specialists, the competence under study does not have a holistic expression either in program documents or in teaching aids. The studied competence is enlarged and integrated with other competencies, allowing the subject to build an individual educational trajectory, to study throughout life, to become an academically and professionally mobile and multicultural personality.

Studies around the world claim efficacy of audiovisual input on L2 learners. For example, the aim of the Co-operative Audiovisual Comprehension (CAC) project, carried out by Suárez and Pujolà (2012) at the Faculty of Education at the UB, is the practice with different kinds of audiovisual texts and tasks selected by the learners themselves, as well as raising self-awareness of their metacognitive strategies needed to answer these tasks. $46 \%$ of participants learning Japanese strongly agree that watching movies with subtitles is useful for learning pronunciation according to the research of Kei Yamaguchi (2020). The same results were claimed by the investigations of E. Bensalem (2016) on Arab ic $[2 ; 12 ; 13]$.

Analysis of the data of the diagnostic stage (testing) of the students of the Engineering Faculty is shown in Fig. 2: students believe that knowledge of a foreign language can contribute to a successful career (37\%) (1), broadens their horizons (31\%) (2), the ability to communicate with a wide range of people (31\%) (3). Most of the group (80\%) (4) watch video materials (videos, films) in a foreign language, including educational ones.

Taking into account the specifics of the chosen profession, $80 \%$ of students are faced with technical documentation in a foreign language and the same percentage of students use video instructions in a foreign language to get acquainted with a new technique. Only $20 \%$ can fully understand the instructions 
and understand it completely, $50 \%$ of students indicated the need to clarify the information received. In this regard, it seems important to us to form the skills of audiovisual teaching of students and to determine the criteria for assessing the formation of foreign language audiovisual competence. In their questionnaires, students indicated that it is easier for them to assimilate the information in a foreign language that they see and hear at the same time (80\%), only $10 \%$ prefer audio sources and $10 \%$ noted presentations in diagnostic tests. This fact confirms the need for the formation of audiovisual competence among students.

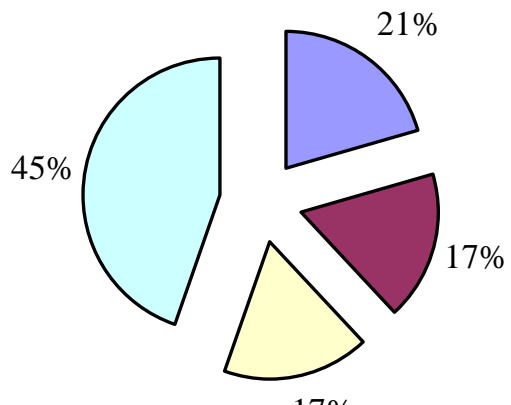

$17 \%$
1 successful career

2 broadens the horizons

3 ability to communicate

4 ability to watch foreign videos

\section{Fig. 2. Contribution of a foreign language}

Answering the question about the choice of the form of audiovisual tasks in foreign language classes, students consider the most effective: watching video with subs $(78 \%)$, language learning applications (61\%), audio recording (58\%), videoconferencing (52\%). The respondents consider less effective: mind mapping (37\%), creating a presentation (44\%), commenting $(42 \%)$ video blog $(45 \%)$, video creation (29\%). These facts indicate the insufficient formation of audiovisual competence among students of engineering specialties. Nevertheless, it should be noted that $80 \%$ of the surveyed students watch video materials (videos, films) in a foreign language, therefore, engineering students have an interest in these materials. Diagnostic testing revealed that $50 \%$ of the students surveyed watched videos, films, technical instructions, etc. on YouTube video hosting, 34\% of students use social media, $14 \%$ prefer educational materials of various kinds. The reasons for choosing a particular media channel are as follows: $47 \%$ of students indicated the availability of an explanation; $33 \%$ of students follow the teacher's recommendations; $22 \%$ of respondents consider visual appeal important; only $18 \%$ of students noted its popularity. According to the survey, $35 \%$ of students turn to media materials for learning a foreign language once or twice a week, $30 \%$ of the group does it once or twice a month, 35\% do it rarely (Fig. 3).

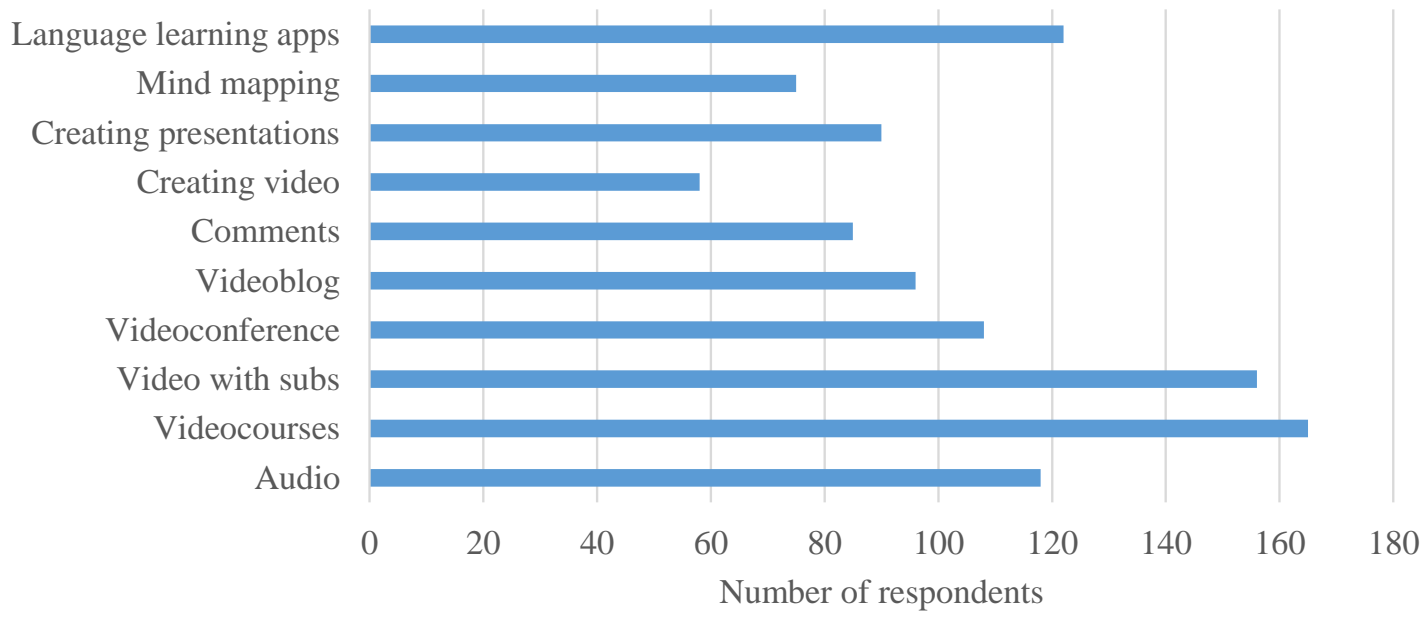

Fig. 3. Content preferences

In everyday life we all have to work with different information. Modern man is faced with the need to think critically, to process and analyze the information that comes to us from different sources. Critical thinking is a good tool for making optimal decisions. The first step for developing critical thinking is to 
evaluate the information that comes to us from the environment. The analysis of students' ability to think critically has shown that $65 \%$ of the polled students question the information received from media sources, $35 \%$ fully trust the information received. Those students who have critical thinking skills check the information obtained in the reference literature and other sources.

\section{Conclusions}

1. Three criteria for formation of audiovisual competence were identified: degree of development of auditive skills and audio visualization abilities, technological readiness, creative activity.

2. Students consider the most effective: watching video with subs (78\%), language learning applications (61\%), audio recording (58\%), videoconferencing (52\%).

3. Due to low motivation the respondents consider less effective productive tasks: mind mapping (37\%), creating a presentation (44\%), commenting (42\%) video blog (45\%), video creation (29\%).

4. It is important to include the following components in the audiovisual competence: information, communication, media-cultural, autopsychological, social interaction and personal development.

\section{References}

[1] Baltova I. Multisensory language teaching in a multidimensional curriculum: The use of authentic bimodal video in core French, Canadian Modern Language Review.- No. 56-1, 1999, pp. 32-48.

[2] Bensalem E. Effects of captioning video clips on vocabulary learning among ESL learners. International Journal of Humanities and Cultural Studies, 3(2), 2016, pp. 381-395.

[3] Gambier Y. The Position of Audiovisual Translation Studies // The Routledge Handbook of Translation Studies. L.: Routledge, 2013, pp. 45-59.

[4] Schwerdtfeger I.C. Sehen und Verstehen. Arbeit mit Filmen im Unterricht Deutsch als Fremdsprache. (See and understand. Working with films in the classroom of German as a foreign language.) - Munich: Langenscheidt, 1989. (In German).

[5] Aboltins A, Atslega S., Sergejeva N., Strupule L. One of opportunities to reduce student dropouts. Engineering for rural development. Jelgava, Latvia. 22-24.05.2019, pp. 1941-1946.

[6] Briede B., Popova N. Self-directed learning of university engineering students in context of fourth industrial revolution. Engineering for rural development. Jelgava, Latvia, 2020. pp. 1594-1600.

[7] Pastukhov A., Sharaya O., Vodolazskaya N., Berezhnaya I. Improving training methods for agricultural engineers. Engineering for rural development. Jelgava, Latvia. 22.05.2020. pp. 82-87.

[8] Harms M. Augen auf im Fremdsprachenunterricht - psychologische und didaktische Aspekte des Lernens mit Bildmedien. (Open your eyes wide for foreign language lessons - psychological and didactic aspects of learning with visual media) In: Duxa, Susanne; Hu, Adelheid \& Schmenk, Barbara (Hrsg.), Crossing borders. People, Languages, Cultures. Festschrift for Inge C. Schwerdtfeger. Tübingen: Narr., 2005, pp. 245-256. (In German).

[9] Competence: Inquiries into its Meaning and Acquisition in Education Settings/ed. By Edmund C. Short. Lanham etc., University Press of America, 1984.

[10] Biechele B. Verbale und nonverbale kommunikative Äußerungsformen bei der Entwicklung des komplexen Verstehens. (Verbal and non-verbal communicative forms of expression in the development of complex understanding) // Journal "German as a foreign language", 25, H.5. 1988, pp. 274-278. (In German).

[11] Safonova V. Cultural Studies as a Didactic Means of Improving Intercultural Language Education // European Journal of Language and Literature Studies. № 3 (1), 2017, pp. 76-84.

[12] Yamaguchi, Kei, "The influence of audiovisual materials on listening comprehension skills in learning Japanese as a foreign language", 2020. Master Thesis. 941.

[13] Suárez, M.M.; Pujolà, J.T. From Listening to Audiovisual Comprehension. Basic Issues in EFL Teaching and learning. Heidelberg, Germany, Universitätsverlag Winter, 2012, pp. 83-91. 